\title{
Squid Have Nociceptors That Display Widespread Long-Term Sensitization and Spontaneous Activity after Bodily Injury
}

\author{
Robyn J. Crook, ${ }^{1}$ Roger T. Hanlon, ${ }^{2}$ and Edgar T. Walters ${ }^{1}$ \\ ${ }^{1}$ Department of Integrative Biology and Pharmacology, University of Texas Medical School at Houston, Houston, Texas 77030, and ${ }^{2}$ Program in Sensory \\ Physiology and Behavior, Marine Biological Laboratory, Woods Hole, Massachusetts 02543
}

Bodily injury in mammals often produces persistent pain that is driven at least in part by long-lasting sensitization and spontaneous activity (SA) in peripheral branches of primary nociceptors near sites of injury. While nociceptors have been described in lower vertebrates and invertebrates, outside of mammals there is limited evidence for peripheral sensitization of primary afferent neurons, and there are no reports of persistent SA being induced in primary afferents by noxious stimulation. Cephalopod molluscs are the most neurally and behaviorally complex invertebrates, with brains rivaling those of some vertebrates in size and complexity. This has fostered the opinion that cephalopods may experience pain, leading some governments to include cephalopods under animal welfare laws. It is not known, however, if cephalopods possess nociceptors, or whether their somatic sensory neurons exhibit nociceptive sensitization. We demonstrate that squid possess nociceptors that selectively encode noxious mechanical but not heat stimuli, and that show long-lasting peripheral sensitization to mechanical stimuli after minor injury to the body. As in mammals, injury in squid can cause persistent SA in peripheral afferents. Unlike mammals, the afferent sensitization and SA are almost as prominent on the contralateral side of the body as they are near an injury. Thus, while squid exhibit peripheral alterations in afferent neurons similar to those that drive persistent pain in mammals, robust changes far from sites of injury in squid suggest that persistently enhanced afferent activity provides much less information about the location of an injury in cephalopods than it does in mammals.

\section{Introduction}

Almost all animals exhibit defensive responses to noxious stimuli that cause incipient or immediate tissue injury (Kavaliers, 1988; Walters, 1994). Primary nociceptors that encode noxious stimuli have been reported in several invertebrate and vertebrate species (Smith and Lewin, 2009), but most research has focused on mammalian nociceptors because of their critical roles in normal and abnormal pain states (Basbaum et al., 2009). A distinctive property of mammalian nociceptors that plays a major role in long-lasting pain is nociceptive sensitization, often expressed after injury or inflammation as increased sensitivity of peripheral branches and sometimes by persistent generation of spontaneous activity (SA) (Gold and Gebhart, 2010; Walters, 2012). Comparison to similar phenomena in nonmammalian species may provide insight into the evolution of mechanisms that can promote

Received Feb. 11, 2013; revised May 3, 2013; accepted May 8, 2013.

Author contributions: R.J.C., R.T.H., and E.T.W. designed research; R.J.C. and E.T.W. performed research; R.J.C. and E.T.W. analyzed data; R.J.C., R.T.H., and E.T.W. wrote the paper.

This work was supported by NSF Grants IOS-1146987 to E.T.W. and IOS-1145478 to R.T.H., and the Baxter Pharmaceuticals Fellowship and Bang Summer Research Fellowship from the Marine Biological Laboratory to R.J.C. We thank Katharine Dickson and the staff of the Marine Resources Center at the Marine Biological Laboratory for assistance with animal care.

The authors declare no competing financial interests.

Correspondence should be addressed to either Robyn J. Crook or Edgar T. Walters, Department of Integrative Biology and Pharmacology, University of Texas Health Science Center at Houston, 6431 Fannin Street, Houston, TX 77030,E-mail: Robyn.Crook@uth.tmc.edu or Edgar.T.Walters@uth.tmc.edu.

DOI:10.1523/JNEUROSCI.0646-13.2013

Copyright $\odot 2013$ the authors $\quad 0270-6474 / 13 / 3310021-06 \$ 15.00 / 0$ pain, but outside of mammals very little is known about nociceptor sensitization (Walters and Moroz, 2009). Sensitization of peripheral branches of nociceptors has not been found in nociceptors of lower vertebrates (Ashley et al., 2007) and has been demonstrated in only two invertebrates, a leech (Pastor et al., 1996) and a gastropod mollusc, Aplysia (Billy and Walters, 1989; Illich and Walters, 1997); less direct evidence for nociceptor sensitization also exists for Drosophila (Babcock et al., 2009). SA in nociceptors persisting for days or longer after injury or inflammation has only been described in mammals (Djouhri et al., 2006; Walters, 2012).

Cephalopods have the largest and most complex brains among the invertebrates, encouraging the opinion that cephalopods may experience pain, and leading some governments to include cephalopods under animal welfare laws (Harvey-Clark, 2011). However, almost nothing is known about their nociceptive systems. Here, we show that a cephalopod-the squid Doryteuthis (Loligo) pealeii-possesses nociceptors that exhibit nociceptive alterations with interesting similarities and differences to those reported in other invertebrates and mammals.

\section{Materials and Methods}

Animal subjects, welfare considerations, and anesthesia. Male and female adult squids were collected near Woods Hole, MA and housed in groups of $2-8$ for up to 2 weeks in running seawater $\left(17-21^{\circ} \mathrm{C}\right)$ and fed small fish (Fundulus spp.) daily. General guidelines for vertebrate animal welfare were followed (Crook and Walters, 2011; Crook et al., 2011). Ani- 
A

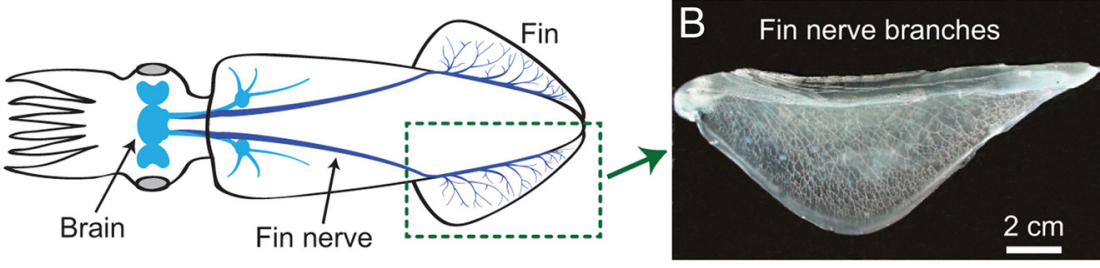

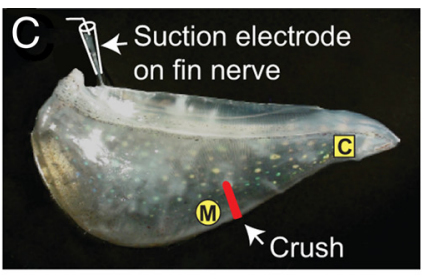

D Evoked mechanosensory activity

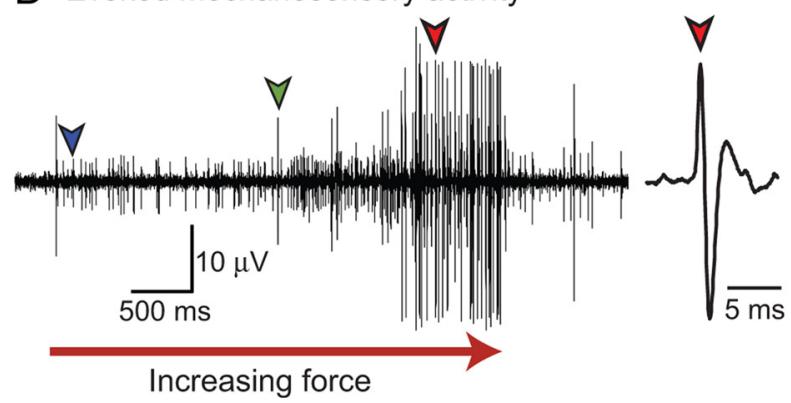

E Activity evoked by von Frey filaments

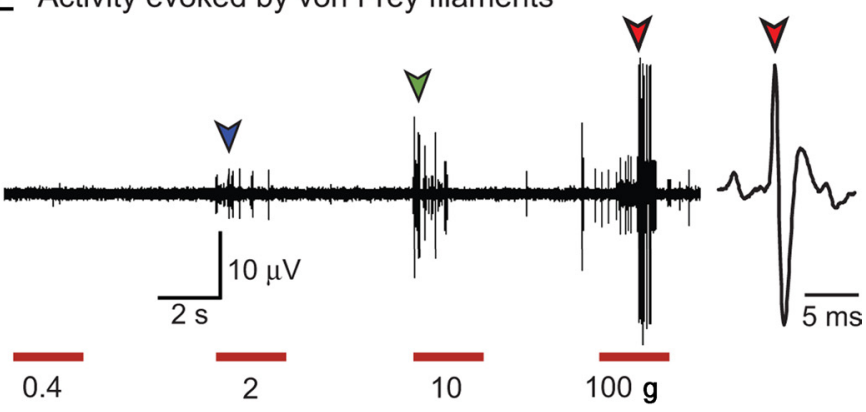

Figure 1. Squid have mechanosensitive nociceptors in their fins. $\boldsymbol{A}$, Innervation of the fin by the fin nerve, which provides the only direct communication with the brain. $\boldsymbol{B}$, Fin nerve branches visualized by injection of air into the main trunk of the fin nerve. $C$, Excised fin-nerve preparation showing the recording electrode, crush injury site, and medial ( $M$ ) and caudal ( $C$ ) test sites on the fin, proximal and distal to the crush site, respectively. $\boldsymbol{D}$, Extracellularly recorded activity evoked by pressing a glass probe (1.5 mm diameter) with progressively increasing force against the fin. Arrows indicate the first appearance of identified units. $\boldsymbol{E}$, Activity at the same site evoked by application of von Frey filaments having progressively greater bending forces (indicated). Colored arrows indicate initial spikes of the same units shown in $\boldsymbol{D}$.

mals in poor health were killed by prolonged immersion in isotonic $\mathrm{MgCl}_{2}$ solution. Sample sizes for studies of in vivo injury were limited to those needed to demonstrate large effects. Experimental injury to the fin (Fig. 1) was small relative to the size of the animal and compared with naturally occurring, survivable injuries observed by us. Injured animals exhibited normal feeding behavior and unchanged mortality rates. Before fin excision, animals were anesthetized by immersion in isotonic $\mathrm{MgCl}_{2}$ solution (Mooney et al., 2010) until chromatophores relaxed and respiratory movements ceased, then killed by decapitation and decerebration.

Injury and noxious stimulation. In both the excised fin-nerve preparation and in vivo, four firm crushes $(\sim 2 \mathrm{~s}$ each) were delivered with serrated forceps ( $2 \mathrm{~mm}$ width) to the site in Figure 1C. Crushes extended $10-15 \mathrm{~mm}$ into the fin. Control fins received light touch from the same forceps. In some excised fins, several $0.5 \mathrm{ml}$ injections of isotonic $\mathrm{MgCl}_{2}$ solution containing Fast Green dye were made subcutaneously and intramuscularly through a 23 gauge needle at the site to be crushed. Visualization both of the dye and relaxation of cutaneous chromatophores demonstrated that the solution spread $<1 \mathrm{~cm}$ from the injury site during the postinjury test period. Peripheral injection of isotonic $\mathrm{MgCl}_{2}$ into molluscs produces local blockade of action potentials (Crook and Walters, 2011).

Testing and extracellular recording. Afferent spike activity was sampled at $20 \mathrm{kHz}$ via a suction electrode on the fin nerve central to the excised fin (Kier et al., 1985). This is the only nerve connecting the fin to the CNS (Young, 1976). Test stimuli were delivered to medial and caudal sites on the fin ( $<10 \mathrm{~mm}$ and $45-70 \mathrm{~mm}$ away from the crush site, respectively; Fig. 1C), using four von Frey filaments (Stoelting), with bending forces of $0.4,2,10$, and $100 \mathrm{~g}(3.9,19.6,98,980 \mathrm{mN})$. Each was applied for $\sim 1.5 \mathrm{~s}$, and spikes were counted during the $1 \mathrm{~s}$ period of maximal firing. In some experiments, thresholds for activity evoked by electrical stimulation of afferent receptive fields were determined by passing constant current pulses ( $1 \mathrm{~ms}$ ) through a $1.5 \mathrm{~mm}$ diameter glass capillary electrode pressed gently against the skin.

Data analysis. Counts of identified single unit spikes were made with Spike Histogram software (ADInstruments) and compared with ANOVA for independent samples or repeated measures. Post hoc comparisons used $t$ tests with sequential Bonferroni correction for multiple comparisons. Rank measures were compared with Kruskal-Wallis and post hoc Mann-Whitney $U$ tests. Critical $\alpha$ values were 0.05 postcorrection. All $p$ values are two-tailed.

\section{Results}

\section{Squid have nociceptors}

The excised squid fin (Fig. 1A) receives extensive innervation from the CNS (Fig. 1B), and afferent activity from neurons innervating the entire fin can be recorded via a suction electrode on the cut end of the fin nerve (Fig. 1C). Pressing a smooth probe against the excised fin with steadily increasing force (Fig. 1D) usually produced a progressive recruitment of single units (indicated by spikes with constant amplitude and waveform) and an increase in firing rate. The same pattern was observed when test stimuli were delivered via a series of four von Frey filaments (Fig. $1 E$ ) that deliver relatively constant forces $(0.2,4$, 10 , or $100 \mathrm{~g}$ ) during bending. At the illustrated test site (Figs. $1 D, E)$, units with smaller spike amplitudes happened to be activated by weaker stimuli than units with larger amplitudes, but no significant differences were found in amplitudes of spikes evoked in single units having low and high mechanical thresholds ( $n=16$ preparations).

Fin mechanoafferents exhibited many different spike amplitudes, but most test sites had units with medium to large spikes (10-80 $\mu \mathrm{V}$ under our recording conditions; Fig. 1D,E). Test stimulation of these sites always evoked responses from multiple units, with a mean of $5.3 \pm 0.3$ single units with spikes $\geq 5 \mu \mathrm{V}$ activated at each site ( $n=32$ test sites in 16 preparations). Of these, one third ( $1.6 \pm 0.3$ units per site) were clearly nociceptive, being activated only by the $100 \mathrm{~g}$ filament (the only filament to produce clear tissue damage with repeated application). No units responded to intense heat $\left(45-55^{\circ} \mathrm{C}\right)$, in contrast to many vertebrate nociceptors that encode noxious heat (Ashley et al., 2007; Basbaum et al., 2009). To compare action potential conduction velocities $(\mathrm{CV})$ we classified single units into groups based on peak-to-peak spike amplitudes: small $(<10 \mu \mathrm{V})$, medium $(10-30 \mu \mathrm{V})$, and large $(>30 \mu \mathrm{V})$. The mean $( \pm \mathrm{SEM}) \mathrm{CV}$ s were $1.9 \pm 0.2,2.7 \pm 0.3$, and $3.3 \pm 0.2 \mathrm{~m} / \mathrm{s}$ for small, medium, and large units, respectively. We did not systematically map receptive fields of nociceptors in this study because repeated probing with 
A Sensitization from test stimulation

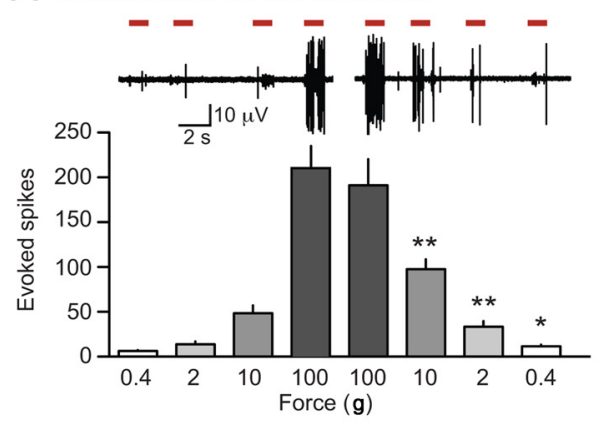

C Fin injury reduces spike thresholds
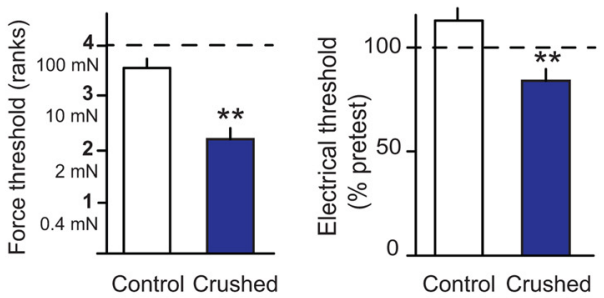

E $\mathrm{MgCl}_{2}$ injection blocks activation by fin injury

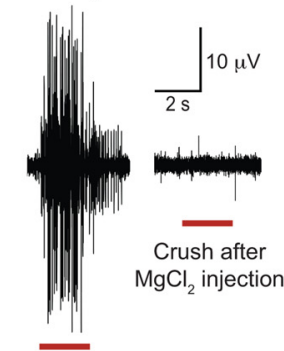

Crush after

SW injection

Figure 2. Squid mechanoafferents show rapid sensitization after noxious stimulation of the excised fin. $\boldsymbol{A}$, Sensitization produced by punctate noxious stimulation. When the ascending sequence of punctate forces used to identify nociceptors was followed by a descending sequence of the same forces, the second application of all but the $100 \mathrm{~g}$ force evoked more spikes than the first application. $\boldsymbol{B}$, Minor crush injury increased activity evoked by the indicated filaments. Note the large units responding to lower forces 5 min after injury. $C$, The same injury reduced mechanosensory (left) and electrical (right) thresholds of units that had been activated solely by $100 \mathrm{~g}$ before crush. $D$, Activity evoked by repeated tests $(10 \mathrm{~g})$ proximal and distal to the crush (Fig. 1C) showed a rapid, prolonged increase after fin injury (arrow). Activity was measured as the total number of spikes $>4 \mu V$ during the $1 \mathrm{~s}$ period of maximal firing. Compared with corresponding responses in control fins, evoked activity was greater in injured fins during all medial tests, and all but the 0.2 min caudal test. $\boldsymbol{E}$, Local injection of isotonic $\mathrm{MgCl}_{2}$ solution blocked immediate activation of afferents by crush injury. Comparisons were to injections with seawater (SW) given before or after the $\mathrm{MgCl}_{2}$ solution. $\boldsymbol{F}$, Localized injection of isotonic $\mathrm{MgCl}_{2}$ solution at the site to be crushed prevented crush-induced enhancement of activity evoked at nearby medial and distant caudal test sites. ${ }^{*} p<0.05,{ }^{* *} p<0.01$.

force sufficient to activate nociceptive fibers produces sensitization (see below) that would confound the sensitizing alterations that were the major objective of this study. However, the receptive fields appeared small, with diameters $<1 \mathrm{~cm}$.

\section{Squid nociceptors show short- and long-term sensitization after noxious stimulation}

Afferent sensitization was observed during a symmetrical sequence of ascending and descending forces delivered by von Frey filaments to the fin at 5-10 s intervals (Fig. 2A). Except for the $100 \mathrm{~g}$ stimulus, significantly more spikes were evoked by the second application of each force than the first $(n=14$, repeated-measures ANOVA, $\left.F_{(1,100)}=7.54, p=0.01\right)$. This sensitization (likely caused by the two $100 \mathrm{~g}$ stimuli) was expressed as decreased mechanosensory threshold in nociceptors; $57 \%$ (46 of 64 units) that had only been activated by the $100 \mathrm{~g}$ filament during the ascending phase were activated by lower forces during the descending phase of the sequence. In contrast, only $28 \%$ of mechanoreceptors ( 12 of 28 units) initially requiring $2 \mathrm{~g}$ for activation were then activated by $0.4 \mathrm{~g}$ during the descending phase $(p=0.01$, Fisher's exact test).

We asked whether minor injury to the excised fin $(n=14)$ sensitizes fin nociceptors. Five minutes after injury, nociceptors close to the crush site $(<10 \mathrm{~mm}$ away) had significant reductions in thresholds for activation both by mechanical (Mann-Whitney $U, W=8.5, p=$ 0.002 ) and by electrical test stimuli (independent samples $t$ test, $t=3.33$, df $=12$, $p=0.006)$ delivered to the same receptive field compared with controls $(n=7$, Fig. $2 C$ ), but CVs were unchanged (unpaired $t$ test, $t=0.26, \mathrm{df}=31, p=0.79$, data not shown). In a separate experiment, repeated tests with a $10 \mathrm{~g}$ filament were delivered to both the medial and caudal test sites on the fin (Fig. 1C) for $30 \mathrm{~min}$ after the injury $(n=9)$. The total number of spikes evoked in injured fins was greater than the preinjury responses to stimulation of both the medial and caudal test sites, and greater than corresponding responses in uncrushed fins (two-factor ANOVA, $F_{(1,40)}=25.31 p=0.001$, pairwise comparisons in Fig. 2D). Sensitization appeared within $\sim 1$ min of injury and persisted for at least $30 \mathrm{~min}$. To test whether this sensitization depended on neural activity generated by the crush at the injury site, we injected isotonic $\mathrm{MgCl}_{2}$ solution subcutaneously and intramuscularly immediately before crushing the fin within the small injected area; seawater was injected into the contralateral fin $(n=5)$. The $\mathrm{MgCl}_{2}$ suppressed nearly all activity evoked by the crush (paired $t$ test, $t=7.21, p=0.002$, Fig. $2 E$ ) and eliminated afferent sensitization both near the injected injury region (medial site, two-factor ANOVA, $F_{(1,8)}=8.52, p=0.01$ ) and distant from the injected injury region (caudal site, $F_{(1,8)}=13.75$, $p=0.006$, Fig. $2 F$ ).

To determine whether afferent sensitization in squid persists after peripheral injury, we produced the same minor crush injury (Fig. 1C) in vivo and waited $30 \mathrm{~min}$ or $24 \mathrm{~h}$ before excising and testing the injured and contralateral fins. Observation of squid swimming freely after fin injury revealed no changes in fin motor function. All injured animals displayed apparent behavioral sensitization to visual stimuli, as described previously for arm injury (Crook et al., 2011). Three animals were tested behaviorally with von Frey filaments delivered to the mantle; in each case threshold 
for escape responses to tactile stimulation decreased after fin injury, consistent with generalized behavioral sensitization. Afferent responses to repeated test stimulation with a $10 \mathrm{~g}$ von Frey filament were significantly increased in fins excised $30 \mathrm{~min}$ after in vivo injury (Fig. $3 A$ ), similar to the afferent sensitization seen after ex vivo injury (Fig. 2D). Afferent responses showed large increases to test stimulation at medial and caudal sites, proximal and distal to the injury site, respectively, $24 \mathrm{~h}$ after injury (Fig. $3 B$ ). Significant enhancement of afferent responses was also observed at corresponding test sites on the contralateral (uninjured) fin $30 \mathrm{~min}$ and $24 \mathrm{~h}$ after unilateral fin injury (Fig. $3 A, B$ ) compared with control fins. Sensitization in the contralateral fin appeared somewhat weaker, but was not significantly different from ipsilateral sensitization.

\section{Afferent neurons in the squid fin exhibit long-lasting spontaneous activity after nearby or distant injury} In vivo fin injury resulted in increased SA in afferent fibers recorded after excision $(n=5)$ compared with fins from uninjured animals $(n=7)$, and this activity was present $30 \mathrm{~min}$ (single-factor ANOVA, $\left.F_{(2,15)}=5.11, p=0.02\right)$ and $24 \mathrm{~h}$ after crush (45 min after excision) $(n=6$ injured, 7 control; single-factor ANOVA, $F_{(2,24)}=16.85, p=0.0001$; Fig. $\left.3 C\right)$. Unexpectedly, significantly enhanced SA was found in the contralateral fin nerve 24 after fin injury (single-factor ANOVA, $\left.F_{(2,24)}=16.85, p=0.0001\right)$. It was not possible to confirm the SA was generated only in nociceptors, but the amplitudes and waveforms of many spontaneous spikes were similar to those of high-threshold single units tested in uninjured preparations. Because the functions of the neurons exhibiting SA could not be determined conclusively, all spikes were counted in this analysis. No significant differences were found in SA before and after crush delivered ex vivo (Fig. $3 C$ ), or when fins that were crushed after excision were compared with uncrushed fins $(n=$ 8 , two-way ANOVA with repeated measures, $F_{(2,6)}=0.19, p=$ $0.67)$, suggesting that induction of persistent SA in peripheral afferents requires neural and/or humoral signals that are present in vivo but absent in the excised fin.

Wild and captive squid engage in agonistic interactions that sometimes result in extensive injuries (Hanlon et al., 1999; Cummins et al., 2011). We tested excised fins from six squid that had received nondebilitating unilateral injury within the previous $24 \mathrm{~h}$ while housed with other squid. Each injury presented as one or more open wounds on the mantle, arms, or fin. These "natural" wounds were several times larger than our experimental fin injury and were associated with the highest rates of SA recorded in the fin nerve (single-factor ANOVA, $F_{(2,19)}=12.53, p=$ 0.0001 ; Fig. $3 D$, left). Evoked responses to mechanical stimulation were similar to those of experimentally injured squid (Fig. $3 D$, right). The degree of SA and sensitization were similar in the animals with $(n=2)$ and without $(n=4)$ obvious injury to a fin, suggesting that injury to regions of the body other than the fin can also produce generalized SA and sensitization.

\section{Discussion}

We show that squid, like most animals (Smith and Lewin, 2009), including other invertebrates (Nicholls and Baylor, 1968; Walters et al., 1983; Tracey et al., 2003; Tobin and Bargmann, 2004) and fish (Martin and Wickelgren, 1971; Sneddon et al., 2003), possess nociceptors that can inform the CNS about the onset of peripheral injury. These neurons are not activated by noxious heat but have mechanical thresholds in the same range ( $\geq 10 \mathrm{~g})$ as nociceptors in mammals (Cain et al., 2001), fish (Ashley et al., 2007), leech (Pastor et al., 1996), and Aplysia (Billy and Walters, 1989). They are likely to be primary nociceptors because peripheral tissue in the mantle region of cephalopods lacks neuronal cell bodies (Hoffmann, 1910; Florey, 1966; Dubas and Boyle, 1985). Although some of the activity evoked by larger forces might represent injury discharge in motor axons, the modest adaptation to prolonged or repeated tissue-damaging forces (cf. Illich and Walters, 1997; Schlegel et al., 2004) and robust nociceptive sensitization (see below) suggest that most of this activity is generated by primary nociceptors.

Noxious stimulation decreased mechanosensory and electrical thresholds in fin nociceptors. Afferent sensitization could be dramatic; single units that initially only responded to the $100 \mathrm{~g}$ 
filament were sometimes activated by the $2 \mathrm{~g}$ filament after fin injury. Sensitization to electrical test stimuli suggests possible hyperexcitability of sensory axons (Weragoda et al., 2004) as well as possible enhancement of sensory transduction. This afferent sensitization is likely to contribute to the sensitization of defensive behavior found after peripheral injury (Crook et al., 2011). Thus, squid, Aplysia, leech, Drosophila, and mammals share an adaptive reaction to injury-sensitization of afferent neurons (Billy and Walters, 1989; Pastor et al., 1996; Babcock et al., 2009; Gold and Gebhart, 2010) that enhances behavioral responsiveness after injury. In mammals, sensitization of nociceptors plays a major role in promoting hyperreflexia and pain after many kinds of injury and inflammation (Gold and Gebhart, 2010; Walters, 2012).

Known nociceptors are usually electrically silent, but mammalian nociceptors sometimes fire spontaneously after injury or inflammation, and ongoing SA may drive spontaneous pain (Djouhri et al., 2006; Walters, 2012). Until now, persistent SA induced by injury has never been described in invertebrate sensory neurons. Injuries causing persistent afferent SA in squid were produced both experimentally and by attacks from other squid, and were similar to wounds on squid observed in the wild (R. T. Hanlon, unpublished observations). Ongoing activity in nociceptors means that information continues to be sent from the periphery to the CNS long after the onset of an injury, which in principle can inform the brain about the status of the injury and potentially drive pain-like sensations. In mammals pain is usually localized to sites of injury and inflammation, and investigations of nociceptor SA have focused on nociceptors that have fibers close to sites of injury and inflammation (Djouhri et al., 2006, 2012). A novel finding in this study is that peripheral injury induced pronounced, long-lasting SA (as well as sensitization to mechanical stimuli) in afferent neurons not only near the injury site but also on the other side of the body. In L. pealeii, fins are innervated separately (Florey, 1966; Hanlon et al., 1999) and are separated by the mantle, suggesting that humoral or CNSmediated factors drive the spread of SA into the opposite fin. Whether injury outside the fin also induces contralateral spread of SA is not yet clear. The frequency of SA recorded in a fin nerve after injury was low compared with the localized, high-frequency, immediate response to injury. Nonetheless, if persistent, lowfrequency SA is generated by afferent neurons in many regions of the body, then the total SA coming into the brain might be substantial.

Generation of afferent SA and the presence of afferent sensitization in the squid distant from as well as close to an injury site suggest that persistently enhanced activity provides little longterm information to the brain about injury location. Lack of localization would be consistent with the enhanced activity being part of a general behavioral state after injury that increases responsiveness to tactile stimulation anywhere on the body surface and to visual stimuli, as observed at the behavioral level in squid after arm injury (Crook et al., 2011). It is also consistent with a lack of evidence for targeted wound-tending behaviors in squid after injury in the laboratory (Crook et al., 2011) and field (Hanlon, unpublished observations). Whereas SA in mammalian nociceptors is assumed to be spatially associated with an injury, promoting pain-related defensive and recuperative behaviors directed at injury sites even in the absence of extrinsic stimulation, SA in squid nociceptors appears to be widespread after injury and might function primarily to drive a generalized vigilance state that includes multiple sensory modalities (Crook et al., 2011). This ongoing afferent information appears to differ significantly from that which drives persistent pain in mammals by not emphasizing the sites of injury.

Our findings do not directly address the speculation that cephalopods experience pain-like states (Mather and Anderson, 2007). We show that squid have sensory neurons that encode noxious stimuli and that exhibit nociceptive sensitization and SA, likely providing motivationally significant information to the brain long after an injury. However, differences between cephalopods and mammals in the spatial organization of long-lasting SA and sensitization in afferent neurons after injury suggest significant differences in the functions and behavioral consequences of nociceptive information processing in cephalopod and mammalian nervous systems.

\section{References}

Ashley PJ, Sneddon LU, McCrohan CR (2007) Nociception in fish: stimulus-response properties of receptors on the head of trout Oncorhynchus mykiss. Brain Res 1166:47-54. CrossRef Medline

Babcock DT, Landry C, Galko MJ (2009) Cytokine signaling mediates UVinduced nociceptive sensitization in Drosophila larvae. Curr Biol 19:799806. CrossRef Medline

Basbaum AI, Bautista DM, Scherrer G, Julius D (2009) Cellular and molecular mechanisms of pain. Cell 139:267-284. CrossRef Medline

Billy AJ, Walters ET (1989) Long-term expansion and sensitization of mechanosensory receptive fields in Aplysia support an activity-dependent model of whole-cell sensory plasticity. J Neurosci 9:1254-1262. Medline

Cain DM, Khasabov SG, Simone DA (2001) Response properties of mechanoreceptors and nociceptors in mouse glabrous skin: an in vivo study. J Neurophysiol 85:1561-1574. Medline

Crook RJ, Walters ET (2011) Nociceptive behavior and physiology of molluscs: animal welfare implications. ILAR J 52:185-195. CrossRef Medline

Crook RJ, Lewis T, Hanlon RT, Walters ET (2011) Peripheral injury induces long-term sensitization of defensive responses to visual and tactile stimuli in the squid Loligo pealeii, Lesueur 1821. J Exp Biol 214:3173-3185. CrossRef Medline

Cummins SF, Boal JG, Buresch KC, Kuanpradit C, Sobhon P, Holm JB, Degnan BM, Nagle GT, Hanlon RT (2011) Extreme aggression in male squid induced by a beta-MSP-like pheromone. Curr Biol 21:322-327. CrossRef Medline

Djouhri L, Koutsikou S, Fang X, McMullan S, Lawson SN (2006) Spontaneous pain, both neuropathic and inflammatory, is related to frequency of spontaneous firing in intact C-fiber nociceptors. J Neurosci 26:12811292. CrossRef Medline

Djouhri L, Fang X, Koutsikou S, Lawson SN (2012) Partial nerve injury induces electrophysiological changes in conducting (uninjured) nociceptive and nonnociceptive DRG neurons: Possible relationships to aspects of peripheral neuropathic pain and paresthesias. Pain 153:1824-1836. CrossRef Medline

Dubas F, Boyle P (1985) Chromatophore motor units in Eledone cirrhosa (Cephalopoda: Octopoda). J Exp Biol 431:415-431.

Florey E (1966) Nervous control and spontaneous activity of the chromatophores of a cephalopod, Loligo opalescens. Comp Biochem Physiol 18: 305-324. CrossRef Medline

Gold MS, Gebhart GF (2010) Nociceptor sensitization in pain pathogenesis. Nat Med 16:1248-1257. CrossRef Medline

Hanlon RT, Maxwell MR, Shashar N, Loew ER, Boyle KL (1999) An ethogram of body patterning behavior in the biomedically and commercially valuable squid Loligo pealei off Cape Cod, Massachusetts. Biol Bull 197: 49-62. CrossRef Medline

Harvey-Clark C (2011) IACUC challenges in invertebrate research. ILAR J 52:213-220. CrossRef Medline

Hoffmann FB (1910) Gibt es in der Muskulatur der Mollusken periphere, kontinuierlich leitende Nervennetze bei Abwesenheit von Ganglienzellen? II: Weitere Untersuchungen an den Chromatophoren der Kephalopoden (Is there in the peripheral muscles of molluscs, continuously conducting nerve networks in the absence of ganglion cells? II: Further studies on the chromatophores of Cephalopods). Pflugers Arch 132:43-81. CrossRef

Illich PA, Walters ET (1997) Mechanosensory neurons innervating Aplysia siphon encode noxious stimuli and display nociceptive sensitization. J Neurosci 17:459-469. Medline 
Kavaliers M (1988) Evolutionary and comparative aspects of nociception. Brain Res Bull 21:923-931. CrossRef Medline

Kier WM, Messenger JB, Miyan JA (1985) Mechanoreceptors in the fins of the cuttlefish, Sepia officianalis. J Exp Biol 119:369-373.

Martin AR, Wickelgren WO (1971) Sensory cells in the spinal cord of the sea lamprey. J Physiol 212:65-83. Medline

Mather JA, Anderson RC (2007) Ethics and invertebrates: a cephalopod perspective. Dis Aquat Organ 75:119-129. CrossRef Medline

Mooney TA, Lee WJ, Hanlon RT (2010) Long-duration anesthetization of squid (Doryteuthis pealeii). Mar Freshw Behav Physiol 43:297303. CrossRef

Nicholls JG, Baylor DA (1968) Specific modalities and receptive fields of sensory neurons in CNS of the leech. J Neurophysiol 31:740-756. Medline

Pastor J, Soria B, Belmonte C (1996) Properties of the nociceptive neurons of the leech segmental ganglion. J Neurophysiol 75:2268-2279. Medline

Schlegel T, Sauer SK, Handwerker HO, Reeh PW (2004) Responsiveness of C-fiber nociceptors to punctate force-controlled stimuli in isolated rat skin: lack of modulation by inflammatory mediators and flurbiprofen. Neurosci Lett 361:163-167. CrossRef Medline

Smith ES, Lewin GR (2009) Nociceptors: a phylogenetic view. J Comp Physiol A Neuroethol Sens Neural Behav Physiol 195:1089-1106. CrossRef Medline

Sneddon LU, Braithwaite VA, Gentle MJ (2003) Do fishes have nociceptors?
Evidence for the evolution of a vertebrate sensory system. Proc Biol Sci 270:1115-1121. CrossRef Medline

Tobin DM, Bargmann CI (2004) Invertebrate nociception: behaviors, neurons and molecules. J Neurobiol 61:161-174. CrossRef Medline

Tracey WD Jr, Wilson RI, Laurent G, Benzer S (2003) painless, a Drosophila gene essential for nociception. Cell 113:261-273. CrossRef Medline

Walters ET (1994) Injury-related behavior and neuronal plasticity: an evolutionary perspective on sensitization, hyperalgesia, and analgesia. Int Rev Neurobiol 36:325-427. CrossRef Medline

Walters ET (2012) Nociceptors as chronic drivers of pain and hyperreflexia after spinal cord injury: an adaptive-maladaptive hyperfunctional state hypothesis. Front Physiol 3:309. Medline

Walters ET, Moroz LL (2009) Molluscan memory of injury: evolutionary insights into chronic pain and neurological disorders. Brain Behav Evol 74:206-218. CrossRef Medline

Walters ET, Byrne JH, Carew TJ, Kandel ER (1983) Mechanoafferent neurons innervating tail of Aplysia. I. Response properties and synaptic connections. J Neurophysiol 50:1522-1542. Medline

Weragoda RM, Ferrer E, Walters ET (2004) Memory-like alterations in Aplysia axons after nerve injury or localized depolarization. J Neurosci 24: 10393-10401. CrossRef Medline

Young JZ (1976) The nervous system of Loligo. II. Suboesophageal centres. Philos Trans R Soc Lond B Biol Sci 274:101-167. CrossRef Medline 